\title{
A fisioterapia sobre a aquisição de funções de vida diária e na memória de portador de Mal de Alzheimer
}

Chaline Flores Franceschi

Miriam Salete Wilk Wisniewski

CADERNO DE RESUMOS

FisiSenectus. Unochapecó Ano 1 - Edição especial - 2013 p. 128

Chaline Flores Franceschi, acadêmica do curso de Fisioterapia da URI - campus de Erechim, chalineft@hotmail.com

\section{Resumo}

Introdução: A doença de Alzheimer (DA) é uma afecção neurodegenerativa progressiva e irreversível, de aparecimento insidioso e que acarreta perda da memória e diversos distúrbios cognitivos. Sua evolução determina importantes deficiências motoras, com limitações para a realização de atividades de vida diária e alteração da marcha. 0 tratamento fisioterapêutico passa a ter grande importância por retardar a progressão das perdas motoras, evitar encurtamentos e deformidades e incentivar a independência do doente. Objetivos: Verificar os efeitos da fisioterapia na aquisição funcional de indivíduo acometido pela DA; Identificar a contribuição que canções e estórias/histórias possam ter sobre sua função cognitiva, e Verificar o comportamento das atividades de vida diária, antes e após a intervenção fisioterapêutica. Metodologia: Estudo do tipo relato de caso, intervencionista, Iongitudinal com abordagem quantitativa. A amostra será composta por um indivíduo do sexo feminino, selecionado de forma intencional, dentre os portadores de Mal de Alzheimer residentes na cidade de Erechim (RS), diagnosticado através de laudo médico e que consentir (e sua família) à participação neste estudo mediante termo de consentimento livre e esclarecido. Inicialmente, o voluntário será submetido a anamnese, seguida da Avaliação da Capacidade Funcional - Stanfordt Health Assessment Questionnaire (HAQ) e da Capacidade Cognitiva por meio do Teste de Mini Mental. Após a avaliação inicial, a voluntária será submetida a intervenção fisioterapêutica direcionada a aquisição de funções diárias, durante dois meses, em três encontros semanais, com duração aproximada de 60 minutos, cujas atividades estão distribuídas em cinco grupos, classificados como: higiene pessoal, alimentação diária, atividades de vida diária gerais, atividades musicais e atividades de leitura. Após o período de intervenção, a voluntária deste estudo será novamente avaliada através do HAQ e Mini Mental. Após a coleta, os dados serão analisados por meio de estatística descritiva. Considerações finais: Este estudo intenciona observar as contribuições que um programa de intervenção fisioterapêutico baseado na simulação e repetição de atividades rotineiras de vida diária, possa proporcionar sobre a aquisição e/ou manutenção da memória e das funções diárias comprometidas em um indivíduo com Mal de Alzheimer.

\section{Palavras-chave}

Doença de Alzheimer. Transtornos da memória. Atividade motora.

Monografia de Conclusão de Curso, em andamento. 